\title{
OPEN Radiation effects on 3D rotating flow of Cu-water nanoliquid with viscous heating and prescribed heat flux using modified Buongiorno model
}

\author{
Wahib Owhaib ${ }^{1}$, Mahanthesh Basavarajappa² \& Wael Al-Kouz ${ }^{1 \bowtie}$
}

In this article, the three-dimensional (3D) flow and heat transport of viscous dissipating $\mathrm{Cu}-\mathrm{H}_{2} \mathrm{O}$ nanoliquid over an elongated plate in a rotating frame of reference is studied by considering the modified Buongiorno model. The mechanisms of haphazard motion and thermo-migration of nanoparticles along with effective nanoliquid properties are comprised in the modified Buongiorno model (MBM). The Rosseland radiative heat flux and prescribed heat flux at the boundary are accounted. The governing nonlinear problem subjected to Prandtl's boundary layer approximation is solved numerically. The consequence of dimensionless parameters on the velocities, temperature, and nanoparticles volume fraction profiles is analyzed via graphical representations. The temperature of the base liquid is improved significantly owing to the existence of copper nanoparticles in it. The phenomenon of rotation improves the structure of the thermal boundary layer, while, the momentum layer thickness gets reduced. The thermal layer structure gets enhanced due to the Brownian movement and thermo-migration of nanoparticles. Moreover, it is shown that temperature enhances owing to the presence of thermal radiation. In addition, it is revealed that the haphazard motion of nanoparticles decays the nanoparticle volume fraction layer thickness. Also, the skin friction coefficients found to have a similar trend for larger values of rotation parameter. Furthermore, the results of the single-phase nanoliquid model are limiting the case of this study.

In recent years, nanoliquids have established prodigious curiosity owing to their extensive applications for example solar collectors, advanced nuclear systems, thermal storage systems, electronic chip cooling, microprocessors, hybrid-powered machines, laser-assisted drug delivery, solar liquid heating/cooling, optoelectronics, and superefficient magnets, etc. Engineered nanoliquids are formed by mixing tiny nano-sized solid particles $(\mathrm{Cu}, \mathrm{Al}, \mathrm{Au}$, $\mathrm{Al}_{2} \mathrm{O}_{3}, \mathrm{TiO}_{2}, \mathrm{ZnO}_{2}$, etc.) and base fluid (such as oil, ethylene glycol, and water). Choi and Eastman ${ }^{1}$ explored that suspending nanoparticles in the water had remarkably improved the thermal efficiency. Theoretical investigation of heat transport is carried out by using two well-known models, viz. Khanafer-Vafai-Lightstone (KVL) model ${ }^{2}$ and Buongiorno two-component nanoliquid model $^{3}$ In the KVL model, the nanoparticles and base fluid possess the same velocity and it includes effective thermophysical properties. Whereas, the Buongiorno model (BM) considers two significant mechanisms such as Brownian motion and thermodiffusion.

Kuznetsov and Nield ${ }^{4}$ considered the Buongiorno two-component nanoliquid model to study the boundary layer of a nanofluid over a vertical plate with natural convection. They found that the temperature field improved due to the random movement of nanoparticles. Afterward, Nield and Kuznetsov ${ }^{5}$ employed the BM model to analyze the Minkowycz problem in the presence of a porous medium. They disclosed that the thermodiffusion phenomenon is favorable for thicker thermal layer thickness. Khan and Pop ${ }^{6}$ studied the nanoliquid dynamics over a flat elongated plate by considering the BM model and Keller box method. They established that the Brownian motion aspect reduces the nanoparticle volume fraction profile. Makinde and Aziz ${ }^{7}$ improvised the work of Khan and Pop ${ }^{6}$ by considering the convective (Newton) boundary condition. Hayat et al. ${ }^{8}$ studied the impact of Newton boundary conditions on the 3D flow of nanofluids using the BM model and couple stress fluid

${ }^{1}$ Department of Mechanical and Maintenance Engineering, German Jordanian University, Amman 11180, Jordan. ${ }^{2}$ Center for Mathematical Needs, Department of Mathematics, CHRIST (Deemed to be University), Bangalore, Karnataka 560029, India. ${ }^{\varpi}$ email: wael.alkouz@gju.edu.jo 


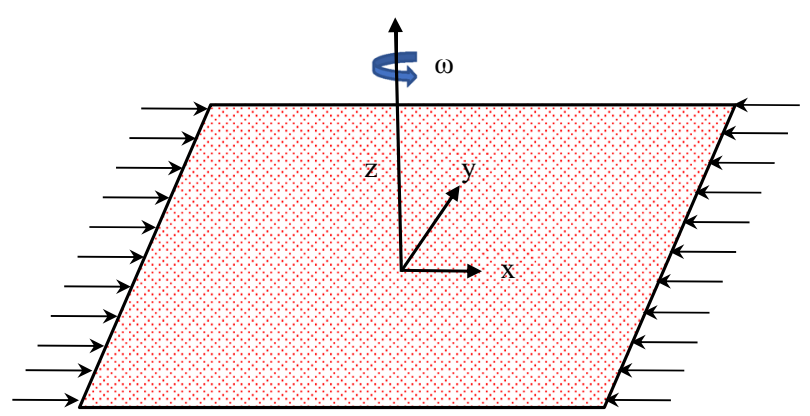

Figure 1. Schematic diagram of the problem under consideration.

model. Homotopy solution for the 3D flow of nanofluid using BM model subjected to the Newton condition and magnetism is proposed by Hayat et al. ${ }^{9}$. The BM model and Oldroyd-B fluid model are utilized by Hayat et al. ${ }^{10}$ to study the 3D stretched flow of nanofluid subjected to magnetism. For a more detailed review of the 3D flow of nanofluid using BM model studies reader can refer to references ${ }^{11-15}$.

The studies in Refs. ${ }^{4-15}$ are more or less similar to the heat and mass transfer problem with the thermodiffusion aspect. Also, the effectual thermophysical properties of nanoliquid affect the flow distributions significantly, hence they can't be ignored and are better to include to obtain accurate results. In this direction, Yang et al. ${ }^{16}$ used the Buongiorno nanoliquid model along with effectual thermo-physical properties of nanoliquids to study the convective thermal transport of nanofluids. Later, this model is well known as the Modified Buongiorno Model (MBM). Malvandi et al. ${ }^{17}$ used the MBM to examine the completely developed flow of nanofluids in an annular pipe. They concluded that the single-phase nanoliquid model results can be recovered from MBM. Malvandi and Ganji ${ }^{18}$ examined the dynamics of nanofluids in a microchannel by using the MBM model. However, the studies related to nanofluid flow using Modified Buongiorno Model are very limited.

The significance of thermal radiation in many industrial and engineering processes like electric power, nondestructive testing, solar cell panels, and many others is vital. Therefore, it is very crucial to comprehend the aspect of thermal radiation to attain the desired quality of products in industrial processes. Sheikholeslami and Rokni ${ }^{19}$ studied the importance of Rosseland thermal radiation and Coulomb force on the dynamics of nanofluids in an enclosure saturated by porous space. They found that the thermal radiation process supports improving the thermal layer thickness. Mahmoud and Megahed ${ }^{20}$ studied the significance of thermal radiation on the dynamics of non-Newtonian fluid with mixed convection and thermal diffusion. The impact of Rosseland radiative heat is examined by Das et al. ${ }^{21}$ on the dynamics of nanoliquid in a micro-channel. Shehzad et al. ${ }^{22}$ investigated to study the thermal radiative heat transfer and 3D flow of nano Jeffrey fluid with magnetism.

Recently, Raza et al. ${ }^{23}$ and Wakif et al..$^{24}$ are investigated the significance and applications of the thermal radiation aspect. Moreover, Alam et al. ${ }^{25}$ used the turbulent SST model to capture the heat transfer characteristics of micro-pin-fin. Several researchers numerically solved the derived 3D flow and energy equations of nanofluids or hybrid nanofluid by the Runge-Kutta-Fehlberg-method (RKF). Furthermore, Baslem et al. ${ }^{26}$ investigated the thermal behavior of porous fin fully wetted with various nanofluids under natural convection and radiation condition. They found that $\mathrm{Cu}$-water was best to enhance the fin heat transfer amongst the investigated nanofluids $\mathrm{Al}_{2} \mathrm{O}_{3}$-water and $\mathrm{TiO}_{2}$-water. In addition. Ganesh Kumar et al. ${ }^{27}$ explained heat transfer behavior influenced by both tangent hyperbolic nanofluid and magnetic field over a moving stretched surface. Additionally, Punith Gowda et al. ${ }^{28}$ presented a 3D nonlinear model for nanofluid flow over an expansion and contraction of a rotating disk featured with thermophoretic particle deposition. In addition, Ahmadian et al. ${ }^{29}$ used homotopy solution and PCM to show the influence of 3D unsteady flow caused by the wavy rotating disk and magnetic field on hybrid nanofluids $\mathrm{Ag} / \mathrm{MgO}$-Water. Ahmadian et al..$^{30}$ studied the Brownian motion and thermophoresis effect on maxwell nanofluid between two stretchable horizontal rotating disks under a magnetic field. They solved their model by boundary value solver (Bvp4c) and RK4. Finally, Lv et al. ${ }^{31}$ used PCM to explore the impact of thermal radiation, magnetic field, and the upshot of Hall current on flow and heat transfer characteristics of carbon nanotubes, and iron ferrite nanofluids flow over a spinning disk.

Inspired by the above-indicated literature and applications, the prime purpose of the current research is to study the 3D rotating flow of nanoliquid over a stretched plate using the modified Buongiorno model (MBM). The modified Buongiorno model comprised haphazard movement and thermo-migration of nanoparticles along with effectual thermophysical properties. The influences of viscous heating, thermal radiation, and prescribed surface heat flux boundary conditions are also scrutinized. The nonlinear partial differential boundary value problem is solved numerically and the results are analyzed. Further, the velocity, temperature, heat transport rate, and mass transport rate are examined for various parameters.

\section{Mathematical formulation}

The rotating $3 \mathrm{D}$ of water-based $\mathrm{Cu}$ nanoliquid over a stretched plate subjected to a rotating frame is considered. The surface heat flux boundary conditions are included. Figure 1 represents a schematic diagram for the problem under investigation.

The transport mechanism for nanoliquid has been addressed by the Modified Buongiorno Model (MBM) that includes the effective nanoliquid properties, haphazard motion of $\mathrm{Cu}$ nanoparticles, and thermo-migration 
mechanism. The rectangular coordinate framework is aligned with $x y$-plane and the fluid region is considered at $z \geq 0$. The $C u$ nanoliquid rotates unvaryingly about $z$-axis with an unvarying rate $\omega$. To characterize the effective thermal conductivity and effectual dynamic viscosity of nanoliquid, the Maxwell-Garnetts ${ }^{2}$ and Brinkman ${ }^{3}$ models are utilized. These models correspond to spherical shape nanoparticles of the volume fraction less than 5-6\%. Utilizing the above-mentioned assumptions, and following Lund et al. ${ }^{32}$, the subsequent boundary-layer expressions are $\left(\sec ^{3,6,9,16}\right)$;

$$
\begin{gathered}
\frac{\partial u}{\partial x}+\frac{\partial v}{\partial y}+\frac{\partial w}{\partial z}=0 \\
\rho_{n l}\left(u \frac{\partial u}{\partial x}+v \frac{\partial u}{\partial y}+w \frac{\partial u}{\partial z}-2 \omega v\right)=\mu_{n l} \frac{\partial^{2} u}{\partial z^{2}} \\
\rho_{n l}\left(u \frac{\partial v}{\partial x}+v \frac{\partial v}{\partial y}+w \frac{\partial v}{\partial z}+2 \omega u\right)=\mu_{n l} \frac{\partial^{2} v}{\partial z^{2}} \\
\left(\rho C_{p}\right)_{n l}\left(u \frac{\partial T}{\partial x}+v \frac{\partial T}{\partial y}+w \frac{\partial T}{\partial z}\right)=k_{n l} \frac{\partial^{2} T}{\partial z^{2}}+\left(\rho C_{p}\right)_{n p}\left\{D_{B} \frac{\partial T}{\partial z} \frac{\partial C}{\partial z}+\frac{D_{T}}{T_{\infty}}\left(\frac{\partial T}{\partial z}\right)^{2}\right\}+\mu_{n l}\left(\left(\frac{\partial u}{\partial z}\right)^{2}+\left(\frac{\partial v}{\partial z}\right)^{2}\right)-\frac{\partial q_{R}}{\partial z} \\
u \frac{\partial C}{\partial x}+v \frac{\partial C}{\partial y}+w \frac{\partial C}{\partial z}=D_{B} \frac{\partial^{2} C}{\partial z^{2}}+\frac{D_{T}}{T_{\infty}} \frac{\partial^{2} T}{\partial z^{2}} .
\end{gathered}
$$

The last term from the right-hand side of Eq. (4) corresponds to the thermal radiation term and it is modeled by using Rosseland's approximation. The $q_{R}$ (radiative heat flux) is given below (see ${ }^{11}$ )

$$
q_{R}=-\frac{4 \alpha}{3 \beta} \frac{\partial T^{4}}{\partial z}
$$

Upon simplifying Eq. (6) through low temperature difference yields (see $\left.{ }^{11}\right)$

$$
\frac{\partial q_{R}}{\partial z}=-\frac{16 \alpha T_{\infty}^{3}}{3 \beta} \frac{\partial^{2} T}{\partial z^{2}} .
$$

Using Eq. (7) in Eq. (4)

$$
\begin{aligned}
\left(\rho C_{p}\right)_{n l}\left(u \frac{\partial T}{\partial x}+v \frac{\partial T}{\partial y}+w \frac{\partial T}{\partial z}\right)= & k_{n l} \frac{\partial^{2} T}{\partial z^{2}}+\left(\rho C_{p}\right)_{n p}\left\{D_{B} \frac{\partial T}{\partial z} \frac{\partial C}{\partial z}+\frac{D_{T}}{T_{\infty}}\left(\frac{\partial T}{\partial z}\right)^{2}\right\} \\
& +\mu_{n l}\left(\left(\frac{\partial u}{\partial z}\right)^{2}+\left(\frac{\partial v}{\partial z}\right)^{2}\right)+\frac{16 \alpha T_{\infty}^{3}}{3 \beta} \frac{\partial^{2} T}{\partial z^{2}},
\end{aligned}
$$

where $u, v$ and $w$ are velocities along $x, y$ and $z$-directions, $v=\frac{\mu}{\rho}$ is the kinematic viscosity, $\mu$ is the dynamic viscosity, $\rho$ is the density, $T$ is the temperature, $C$ is the dimensionless nanoparticle volume fraction, $\alpha=\frac{k}{\rho C_{p}}$ is the thermal diffusivity, $k$ is the thermal conductivity, $\rho C_{p}$ is the specific heat, $D_{B}$ is the coefficient of Brownian diffusion, $D_{T}$ is the coefficient of thermo-migration diffusion, $\alpha$ is the Stefan-Boltzmann constant and $\beta$ is the mean absorption factor. The boundary conditions are

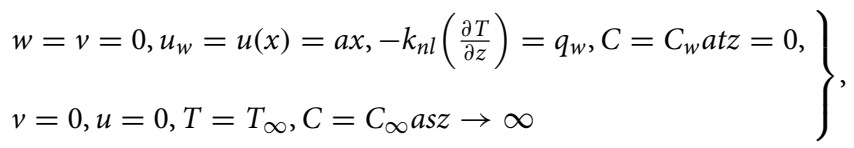

where $a>0$ is stretching rate and $q_{w}=\left(T_{w}-T_{\infty}\right) k_{l} \sqrt{a / v_{l}}$ is constant heat flux.

The effective density and specific heat of water-based $\mathrm{Cu}$ nanoliquid are as follows:

$$
\begin{gathered}
\rho_{n l}=(1-\phi) \rho_{l}+\phi \rho_{n p}, \\
\left(\rho C_{p}\right)_{n l}=(1-\phi)\left(\rho C_{p}\right)_{l}+\phi\left(\rho C_{p}\right)_{n p},
\end{gathered}
$$

Brinkman model for dynamic viscosity and Maxwell model for thermal conductivity are used.

$$
\frac{\mu_{n l}}{\mu_{l}}=\frac{1}{(1-\phi)^{2.5}}
$$




$$
\frac{k_{n l}}{k_{l}}=\frac{k_{n p}+2 k_{l}-2 \phi\left(k_{l}-k_{n p}\right)}{k_{n p}+2 k_{l}+\phi\left(k_{l}-k_{n p}\right)},
$$

The subscripts $l, n l$, and $n p$ indicate base liquid, nanoliquid, and nanoparticles correspondingly. Because of Eqs. (10)-(12) and considering

$$
\begin{gathered}
\zeta=z \sqrt{\frac{u_{w}}{x v_{l}}}, u=a f^{\prime}(\zeta), v=\operatorname{axg}(\zeta), w=-\sqrt{v_{l} a} f(\zeta), \\
T=\left(T_{w}-T_{\infty}\right) \theta(\zeta)+T_{\infty}, C=\left(C_{w}-C_{\infty}\right) \Theta(\zeta)+C_{\infty} .
\end{gathered}
$$

Equation (1) is satisfied and Eqs. (2), (3), (5), (8) and (9) are reduced to

$$
\left.\begin{array}{c}
\frac{\Psi_{2}}{\Psi_{1}} f^{\prime \prime \prime}+f^{\prime \prime}-f^{\prime 2}+2 R o g=0, \\
\frac{\Psi_{2}}{\Psi_{1}} g^{\prime \prime}+f g^{\prime}-g f^{\prime}-2 R o f^{\prime}=0, \\
\frac{\Psi_{4}+R d}{P r} \theta^{\prime \prime}+\Psi_{3} f \theta^{\prime}+N b \Theta^{\prime} \theta^{\prime}+N t \theta^{\prime 2}+\Psi_{2} E c\left[\left(f^{\prime \prime}\right)^{2}+\left(g^{\prime}\right)^{2}\right]=0, \\
\Theta^{\prime \prime}+\frac{N t}{N b} \theta^{\prime \prime}+\operatorname{LePrf} \Theta^{\prime}=0, \\
f=0, g=0, f^{\prime}=1, \theta^{\prime}=\frac{-1}{\Psi_{4}}, \Theta=1 a t \zeta=0 \\
f^{\prime}=0, g=0, \theta=0, \Theta=0 a s \zeta \rightarrow \infty .
\end{array}\right\},
$$

where $\zeta$-similarity variable, $f, g, \theta$, and $\Theta$ are dimensionless axial velocity, transverse velocity, temperature, and nanoparticle volume fraction correspondingly, prime denotes the differentiation with respect to $\zeta, \operatorname{Pr}=\frac{\left(C_{p} \mu\right)_{l}}{k_{l}}$ (Prandtl number), $R o=\frac{\omega}{a}$ (rotation parameter), $L e=\frac{\alpha_{l}}{D_{B}}$ (Lewis number), $N t=\frac{\left(\rho C_{p}\right)_{n p} D_{T}\left(T_{w}-T_{\infty}\right)}{\left(\rho C_{p}\right)_{l} T_{\infty} v_{l}}$ (thermophoresis parameter), $N b=\frac{\left(\rho C_{p}\right)_{n p} D_{B}\left(C_{w}-C_{\infty}\right)}{\left(\rho C_{p}\right)_{l} \nu_{l}}$ (Brownian motion parameter), $R d=\frac{16 \alpha T_{\infty}^{3}}{3 k_{l} \beta}$ (thermal radiation parameter), $E c=\frac{u_{w}^{2}}{C_{p l}\left(T_{w}-T_{\infty}\right)}($ Eckert number $)$,

$$
\begin{gathered}
\Psi_{1}=(1-\phi)+\phi \frac{\rho_{n p}}{\rho_{l}}, \\
\Psi_{2}=\frac{1}{(1-\phi)^{2.5}}, \\
\Psi_{3}=(1-\phi)+\phi\left(\rho C_{p}\right)_{n p} /\left(\rho C_{p}\right)_{l} \text {, and } \\
\Psi_{4}=\left(k_{n p}+2 k_{l}-2 \phi\left(k_{l}-k_{n p}\right)\right) /\left(k_{n p}+2 k_{l}+\phi\left(k_{l}-k_{n p}\right)\right) .
\end{gathered}
$$

The expressions of dimensionless local friction factors $\left(S f_{x} \& S f_{y}\right)$, local Nusselt number $\left(N u_{x}\right)$ and local Sherwood number $\left(S h_{x}\right)$ are

$$
\begin{gathered}
R e_{x}^{0.5} S f_{x}=\Psi_{2} f^{\prime \prime}(0), \\
R e_{x}^{0.5} S f_{y}=\Psi_{2} g^{\prime}(0), \\
R e_{x}^{-0.5} N u_{x}=-\frac{\Psi_{4}(1+R d)}{\theta(0)}, \\
R e_{x}^{-0.5} S h_{x}=-\Theta^{\prime}(0),
\end{gathered}
$$

where $R e_{x}=\frac{x u_{w}}{v_{l}}$ is local Reynolds number. 


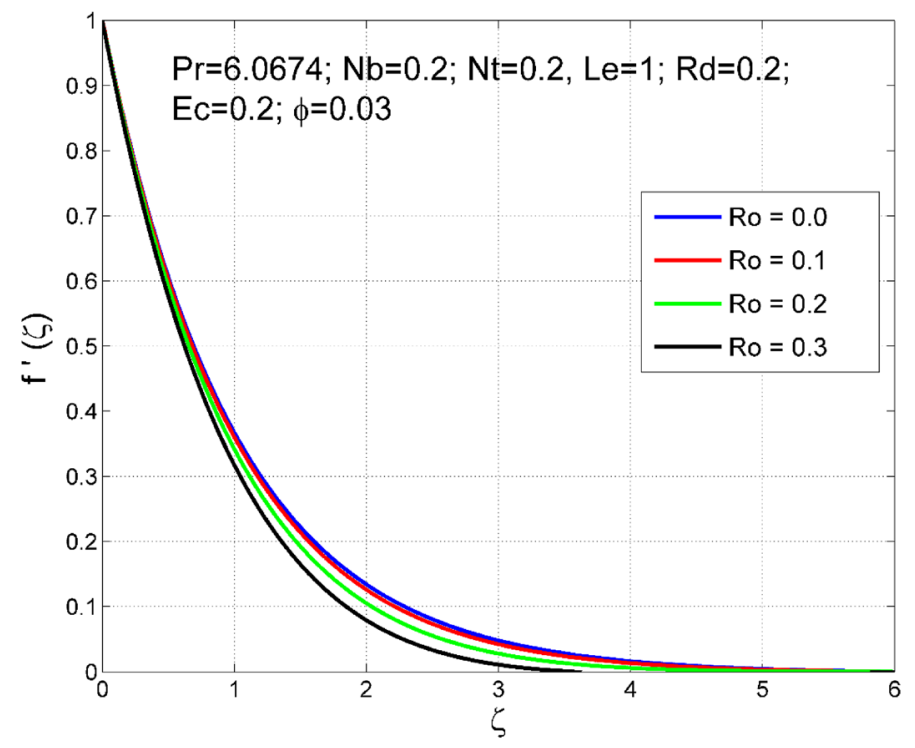

Figure 2. Effect of $\operatorname{Ro}$ on $f^{\prime}(\zeta)$.

\section{Numerical technique}

The defined nonlinear problem in Eqs. (14)-(18) is solved numerically using the Finite Difference Method based bvp5c alogorithm. Now set $f=y_{1}, f^{\prime}=y_{2}, f^{\prime \prime}=y_{3}, g=y_{4}, g^{\prime}=y_{5}, \theta=y_{6}, \theta^{\prime}=y_{7}, \Theta=y_{8}$ and $\Theta^{\prime}=y_{9}$ to obtain the following single-order differential system:

$$
\begin{gathered}
y_{1}^{\prime}=y_{2}, \\
y_{2}^{\prime}=y_{3}, \\
y_{3}^{\prime}=\frac{\Psi_{2}}{\Psi_{1}}\left(y_{2}^{2}-y_{1} y_{3}-2 R o y_{4}\right), \\
y_{4}^{\prime}=y_{5}, \\
y_{5}^{\prime}=\frac{\Psi_{2}}{\Psi_{1}}\left(2 R o y_{2}+y_{2} y_{4}-y_{1} y_{5}\right), \\
y_{7}^{\prime}=\frac{-\operatorname{Pr}\left\{\Psi_{3} y_{1} y_{7}+N b y_{7} y_{9}+N t\left(y_{7}\right)^{2}+\Psi_{2} E c\left(y_{3}^{2}+y_{5}^{2}\right)\right\}}{\Psi_{4}+R d}, \\
y_{9}^{\prime}=-L e P r y_{1} y_{10}+\left(\frac{N t}{N b}\right)\left(\frac{\operatorname{Pr}\left\{\Psi_{3} y_{1} y_{7}+N b y_{7} y_{9}+N t\left(y_{7}\right)^{2}+\Psi_{2} E c\left(y_{3}^{2}+y_{5}^{2}\right)\right\}}{\Psi_{4}+R d}\right),
\end{gathered}
$$

with

$$
\begin{gathered}
y_{1}(0)=0, y_{4}(0)=0, y_{2}(0)=1, y_{8}(0)=1, y_{7}(0)=\frac{-1}{\Psi_{4}}, \\
y_{2}(\infty)=0, y_{4}(\infty)=0, y_{6}(\infty)=0, y_{7}(\infty)=0 .
\end{gathered}
$$

The above system is solved using the bvp 5 c routine of MATLAB (see Shampine et al. ${ }^{33}$ ). This routine integrates a system of differential equations of the form $y^{\prime}=f(x, y)$ specified, subject to the boundary conditions. Details of the algorithm used in the solution are provided in the "Appendix" section of this article. This method 


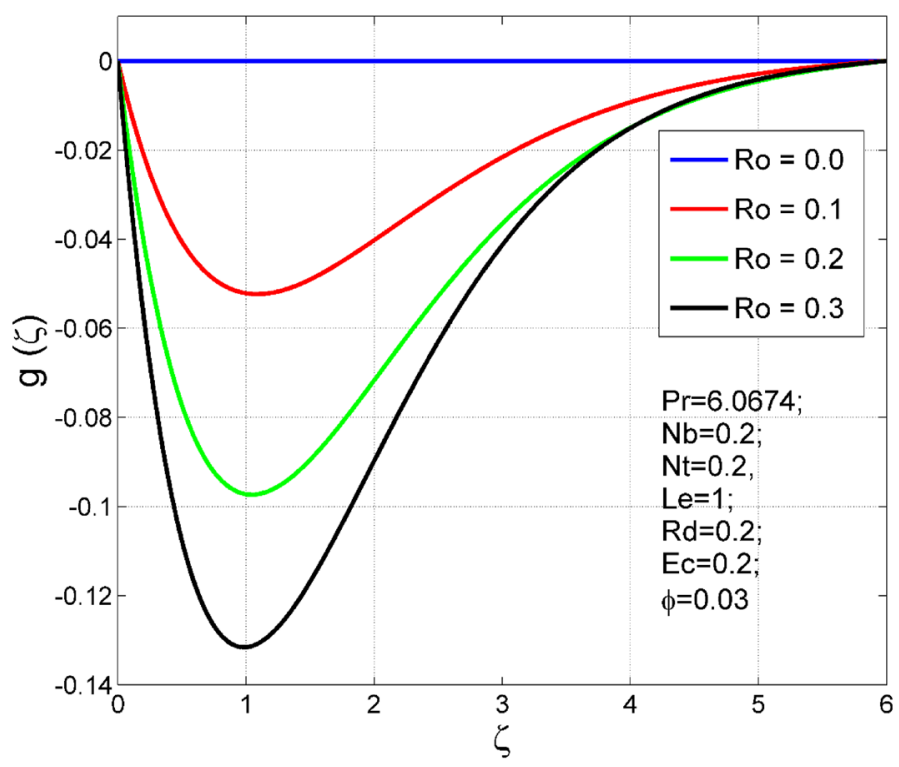

Figure 3. Effect of $\operatorname{Ro}$ on $g(\zeta)$.

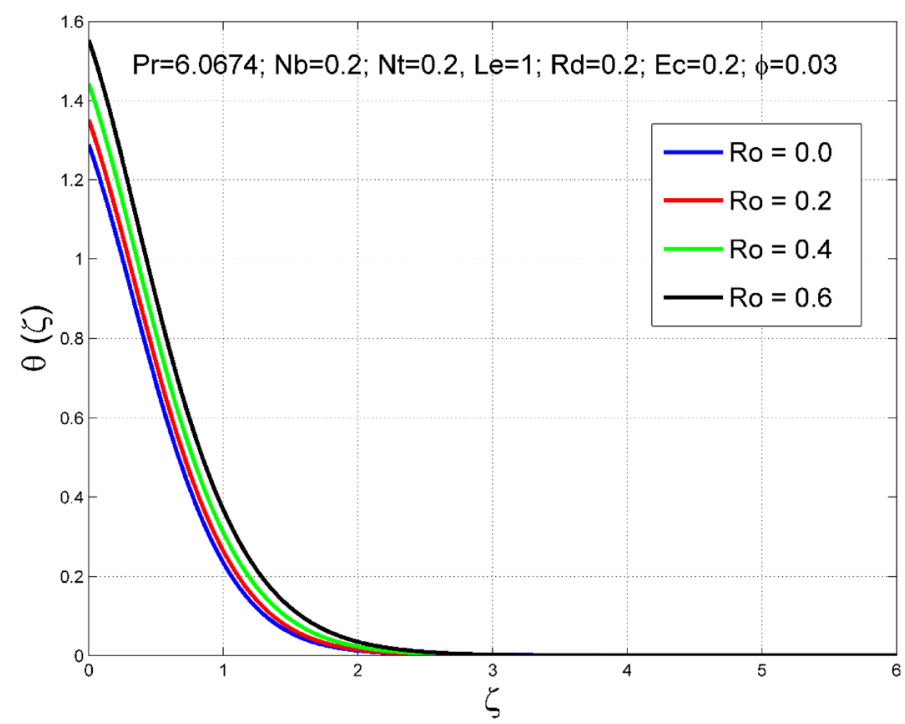

Figure 4. Effect of $\operatorname{Ro}$ on $\theta(\zeta)$.

is used extensively by many researchers to solve the nonlinear problem, further, they have validated the method used.

\section{Interpretation of the outcomes}

Figures $2,3,4,5,6,7,8,9,10,11,12,13,14,15,16,17,18,19,20$ and 21 are presented to analyze the significance of numerous physical parameters such as rotation parameter $(R o)$, Brownian motion parameter $(N b)$, thermo-migration parameter $(N t)$, Eckert number $(E c)$, Rosseland radiation parameter $(R d)$, and copper nanoparticles volume fraction $(\phi)$ on velocities $\left(f^{\prime}(\zeta), g(\zeta)\right)$, temperature $(\theta(\zeta))$, nanoparticle volume fraction $(\Theta(\zeta))$, friction coefficients at the plate $\left(R e_{x}^{0.5} S f_{x} \& R e_{x}^{0.5} S f_{y}\right)$, Sherwood number $\left(R e_{x}^{-0.5} S h_{x}\right)$ and Nusselt number $\left(R e_{x}^{-0.5} N u_{x}\right)$ distributions. The numerical simulations are carried out for $\operatorname{Pr}=6.0674, R o=0.5, N b=N t=0.2, L e=1, R d=0.2, E c=0.2$, and $\phi=3 \%$.

The stimulus of rotation factor $(R o)$ on velocities $\left(f^{\prime}(\zeta), g(\zeta)\right)$, temperature $(\theta(\zeta))$, and nanoparticle volume fraction $(\Theta(\zeta))$ is presented in Figs. 2, 3, 4 and 5 respectively. The magnitude of axial velocity $f^{\prime}(\zeta)$ and transverse velocity decreases by increasing values of rotation factor $(R o)$. The rotation factor $(R o)$ is a ratio of angular velocity to stretching rate. Larger values of $R o$ indicate to lower stretching rate, due to which, the velocities are diminished for larger Ro. Further, in the absence of rotation $(R o=0)$ there is no $g(\zeta)$ and the $f^{\prime}(\zeta)$ is found to be higher. An increasing trend is observed for the thermal and nanoparticle volume fraction layer structure 


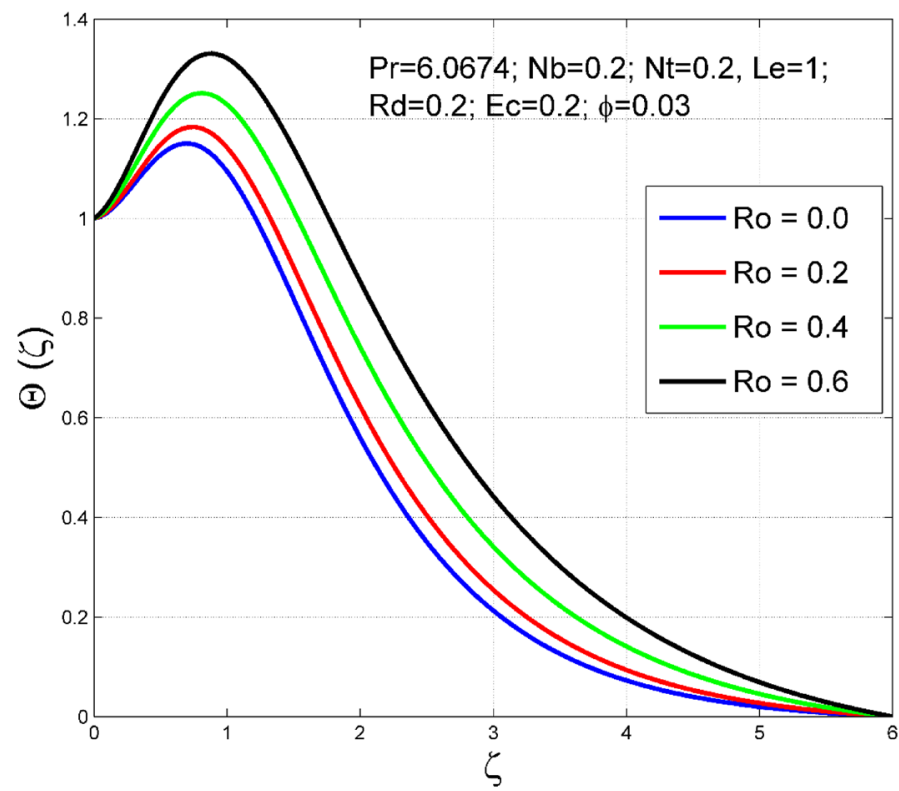

Figure 5. Effect of $\operatorname{Ro}$ on $\Theta(\zeta)$.

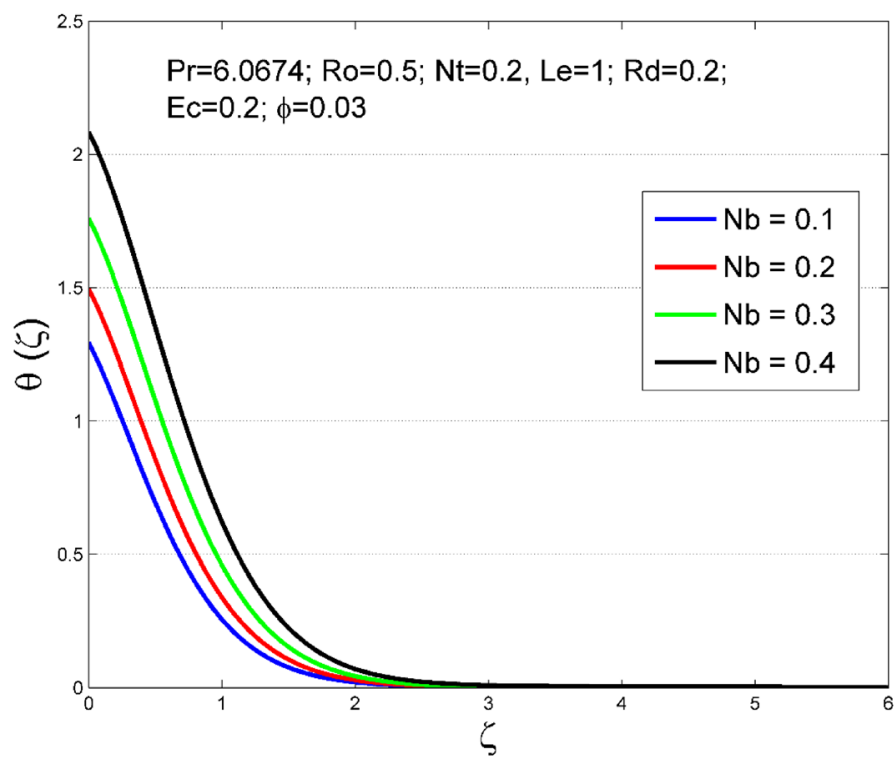

Figure 6. Effect of $N b$ on $\theta(\zeta)$

when Ro values are increased (see Figs. 4, 5). Figures 6 and 7 describe how the haphazard movement of nanoparticles $(\mathrm{Nb})$ affects the temperature $(\theta(\zeta))$ and nanoparticle volume fraction $(\Theta(\zeta))$ fields. A diminishing trend of nanoparticle volume fraction $(\Theta(\zeta))$ is perceived for advanced values of $\mathrm{Nb}$, while, an opposite trend is observed for temperature $(\theta(\zeta))$ profile. The haphazard collision of suspended nanoparticles in water produces supplementary heat in the system and thereby the magnitude of the temperature field increases.

The consequence of $N t$ on temperature $(\theta(\zeta))$ and nanoparticle volume fraction $(\Theta(\zeta))$ distributions are delineated in Figs. 8 and 9. The thermodiffusion factor is a quantity that measures the intensity of force produced by the thermal gradient in the liquid system. As $N t$ increases, the additional internal heat supplied to the liquid system via thermal gradient increases, and thereby both the temperature $(\theta(\zeta))$ and nanoparticle volume fraction $(\Theta(\zeta))$ are enhanced.

Figures 10 and 11 display the impact of viscous heating $(E c)$ on temperature $(\theta(\zeta))$ and nanoparticle volume fraction $(\Theta(\zeta))$. A significant improvement occurred in both $\theta(\zeta)$ and $\Theta(\zeta)$ via higher $E c$. Higher $E c$ corresponds 


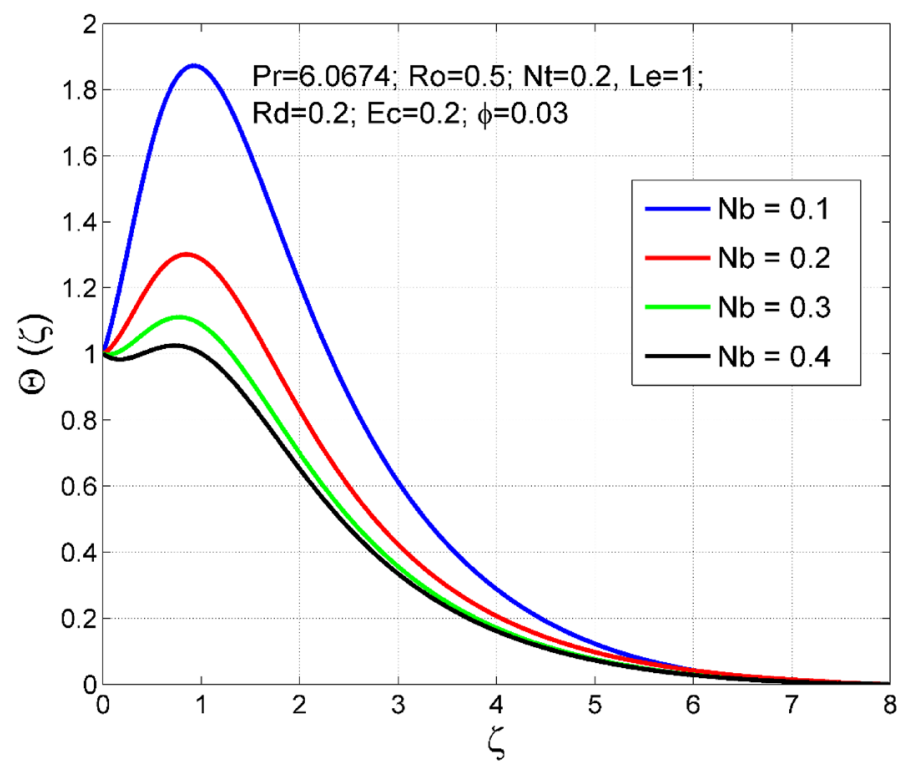

Figure 7. Effect of $N b$ on $\Theta(\zeta)$.

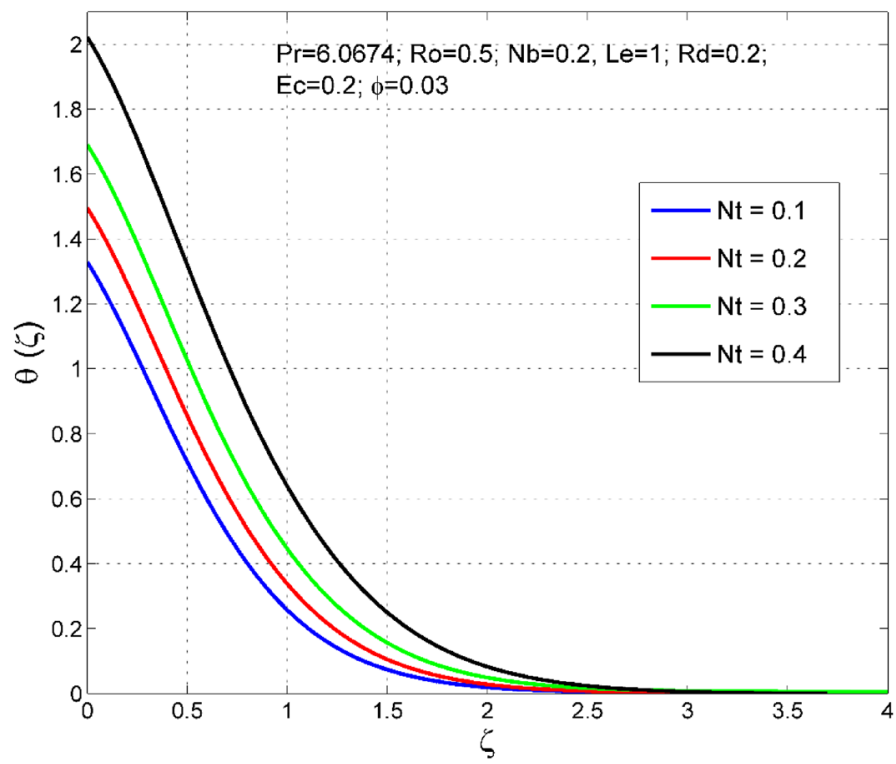

Figure 8. Effect of $N t$ on $\theta(\zeta)$.

to stronger kinetic energy which causes an enhancement in the magnitude of temperature and volume fraction of $C u$ nanoparticles. Figures 12 and 13 are drawn to visualize the influence of Rosseland thermal radiation $(R d)$ on temperature $(\theta(\zeta))$ and nanoparticle volume fraction $(\Theta(\zeta))$. Both $\theta(\zeta)$ and $\Theta(\zeta)$ are upsurged for increasing numeric values of $R d$. Physically, the factor of mean absorption has an inverse relation with $R d$. Consequently, larger $R d$ implies a lower mean absorption factor which improves supplementary heat, and as a result, nanoliquid temperature is enhanced. Figures 14 and 15 are drawn to examine the influence of $\phi$ on $\theta(\zeta)$ and $\Theta(\zeta)$. Enhancing tendency of temperature $\theta(\zeta)$ and nanoparticle volume fraction $\Theta(\zeta)$ is seen for larger values of $\phi$. The thermal conductivity of base liquid water enhances by conveying $\mathrm{Cu}$ nanoparticles. Stronger thermal diffusivity is responsible for the development of thermal and solute layer structures.

Figures 16 and 17 are plotted to analyze the behavior of friction factors at the plate along $x$ and $y$ directions $\left(R e_{x}^{0.5} S f_{x}, R e_{x}^{0.5} S f_{y}\right)$, Nusselt number $\operatorname{Re}_{\mathrm{x}}^{-0.5} N u_{x}$ and Sherwood number $R e_{x}^{-0.5} S h_{x}$ when $N b=N t=0.2, L e=1, \operatorname{Pr}=6.0674, R o=0.5, E c=0.2, \phi=3 \%$, and $R d=0.2$ except when they are diverse. 


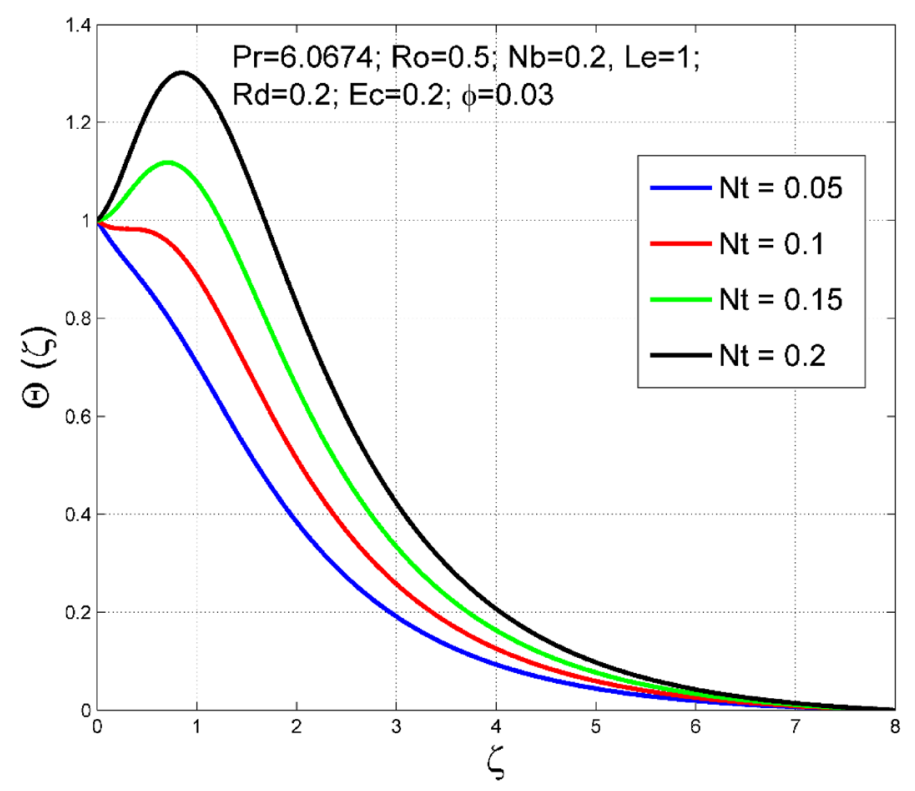

Figure 9. Effect of $N t$ on $\Theta(\zeta)$.

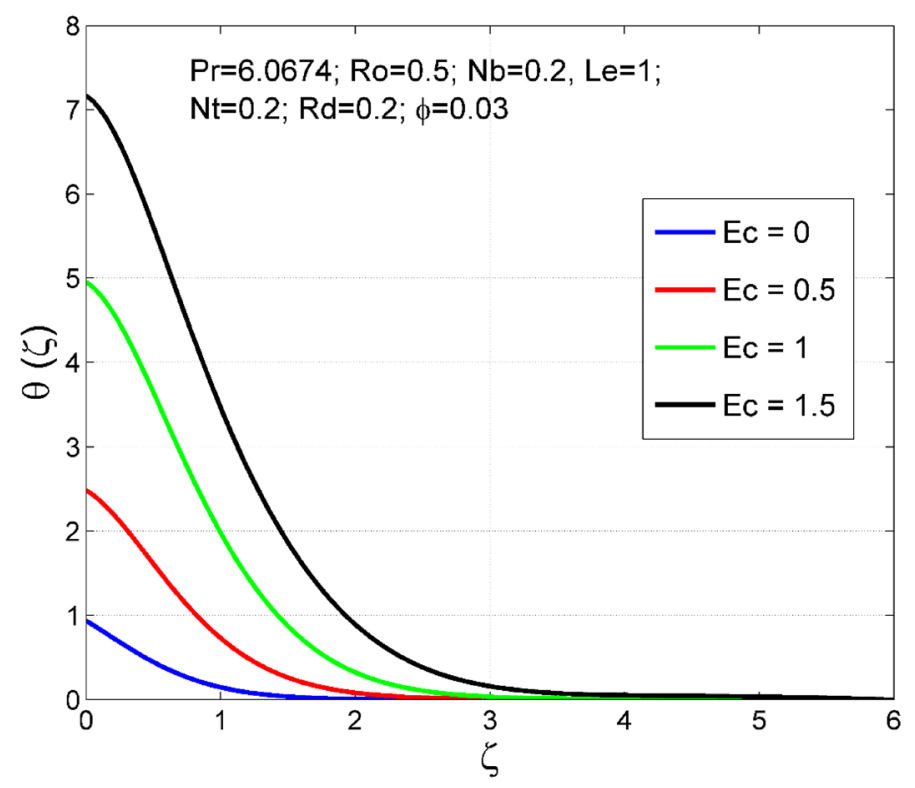

Figure 10. Effect of $E c$ on $\theta(\zeta)$.

Figures 16 and 17 depict the effects of $R o$ and $\phi$ on $R e_{x}^{0.5} S f_{x}$ and $R e_{x}^{0.5} S f_{y}$. Figure 16 exhibit that $R e_{x}^{0.5} S f_{x}$ decreases for larger $R o$ and $\phi$. A similar trend is observed for $R e_{x}^{0.5} S f_{y}$ when $R o$ and $\phi$ are gets increased. Figure 18 designate that the $\operatorname{Re}_{x}^{-0.5} N u_{x}$ is an increasing property of both $N b$ and $E c$. Figure 19 demonstrates the impact of $N b$ and $E c$ on $R e_{x}^{-0.5} S h_{x}$. It is seen that $R e_{x}^{-0.5} S h_{x}$ enhances for larger values of $N b$ and $E c$. Figures 20 and 21 explain the behavior of the Nusselt number $\mathrm{Re}_{\mathrm{x}}^{-0.5} \mathrm{Nu} u_{x}$ and Sherwood number $R e_{x}^{-0.5} S h_{x}$ for distinct values of $N t$ and $R d$. We have seen that $\mathrm{Re}_{\mathrm{x}}^{-0.5} \mathrm{~N} u_{x}$ enhances for larger $R d$ while it shows the decaying trend for greater values of $N t$. Further, the $R e_{x}^{-0.5} S h_{x}$ reduces for increasing values of $R d$. 


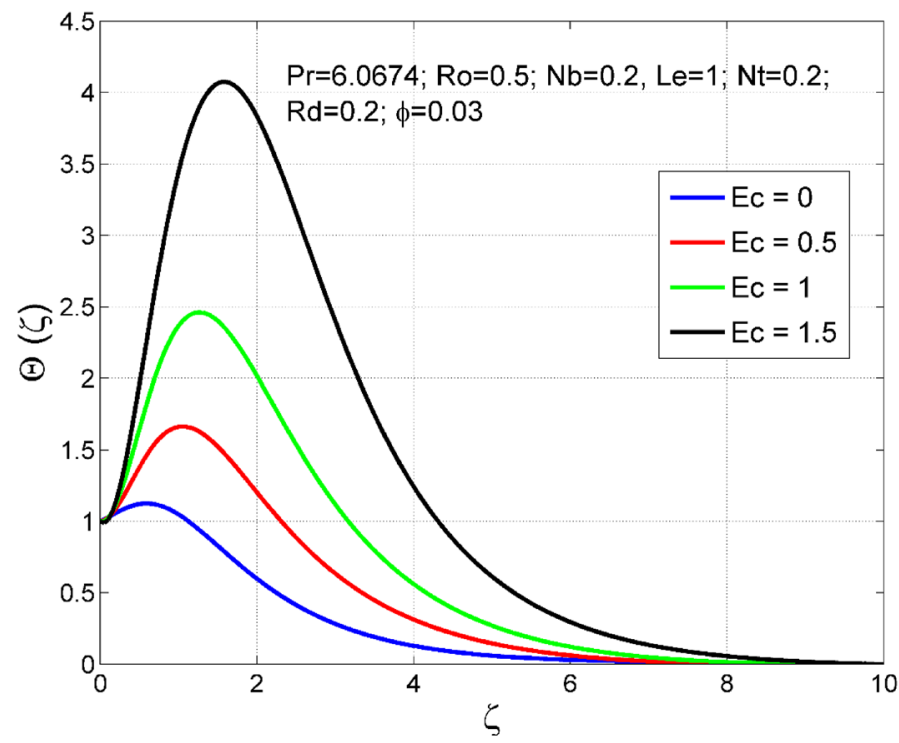

Figure 11. Effect of $E c$ on $\Theta(\zeta)$.

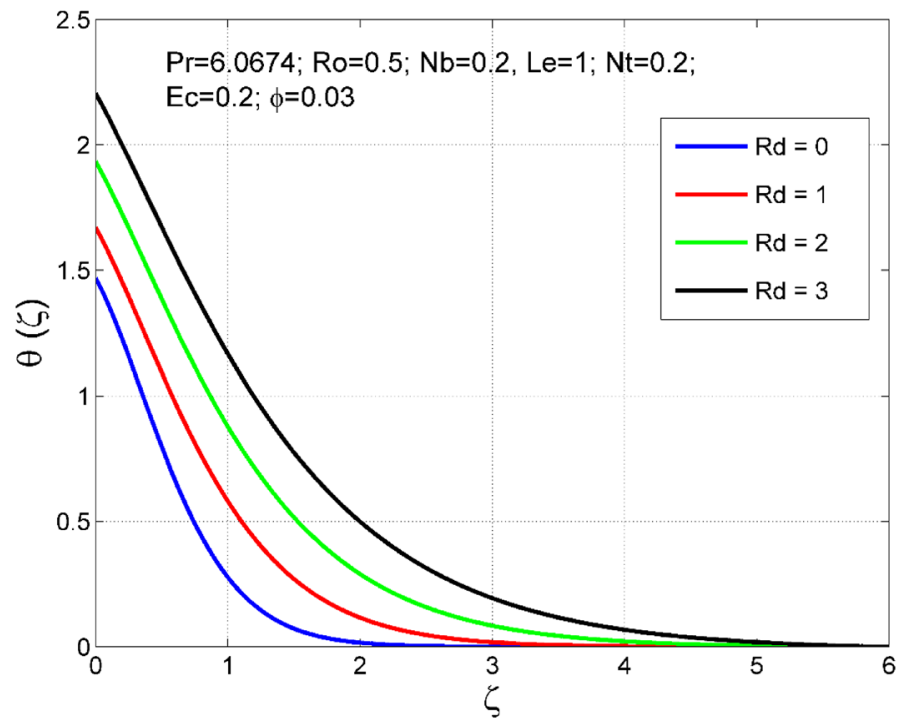

Figure 12. Effect of $R d$ on $\theta(\zeta)$.

\section{Final remarks}

The key outcomes of the present study are:

- The temperature is found to be higher due to constant heat flux condition.

- The viscous dissipation effect leads to an enhancement of nanoparticle volume fraction and temperature profiles.

- The rotation of the plate exhibits decreasing behavior of velocity components.

- The nanoparticle volume fraction revelations increasing behavior of thermal and solute layer thickness. 


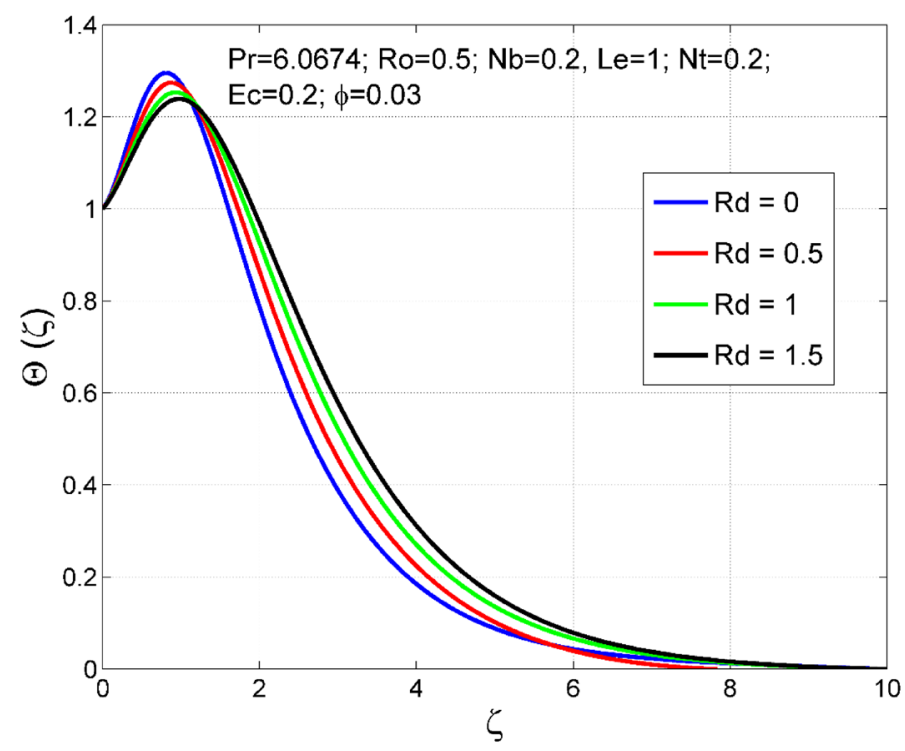

Figure 13. Effect of $R d$ on $\Theta(\zeta)$.

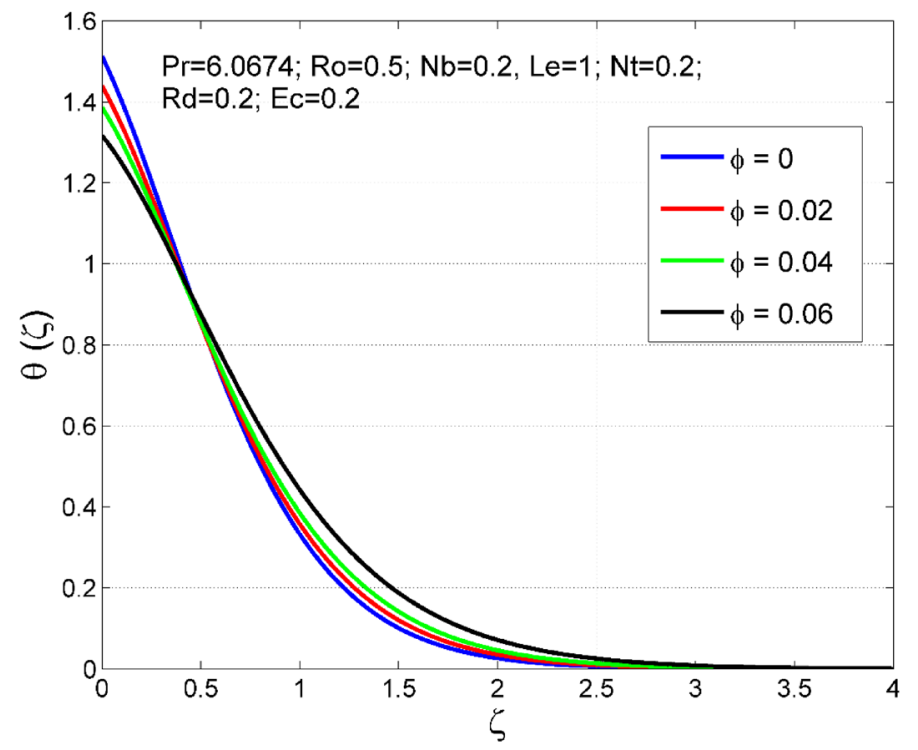

Figure 14. Effect of $\phi$ on $\theta(\zeta)$.

- Temperature enhances owing to the presence of thermal radiation.

- The temperature profile and its related boundary layer thickness improve for larger Brownian movement parameter and thermophoresis parameter.

- The haphazard motion of nanoparticles decays the nanoparticle volume fraction layer thickness.

- Skin friction coefficients have a similar trend for larger values of rotation parameter. 


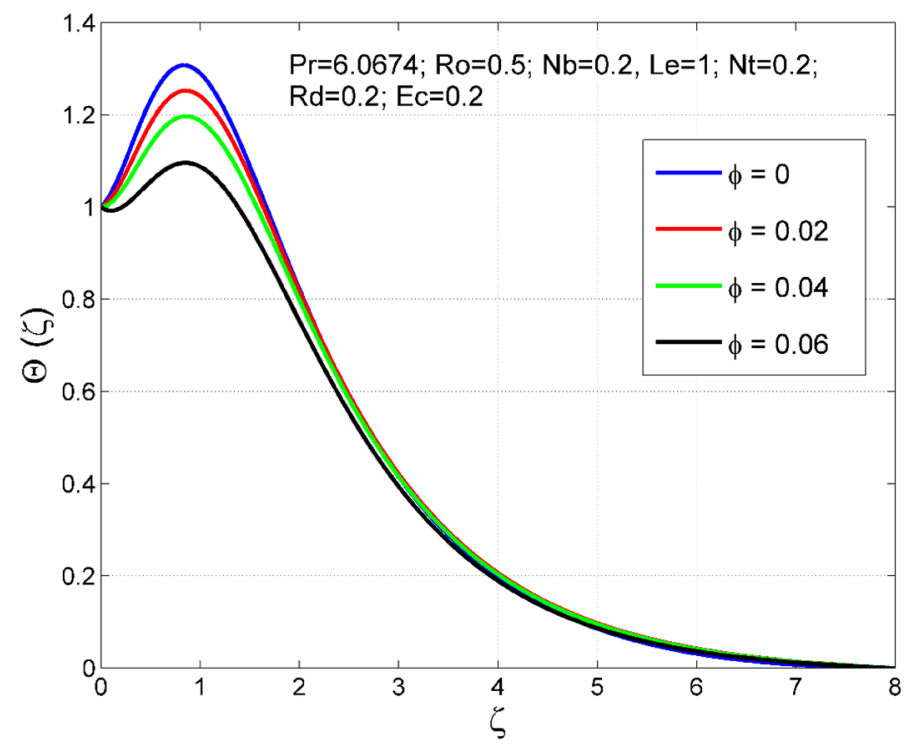

Figure 15. Effect of $\phi$ on $\Theta(\zeta)$.

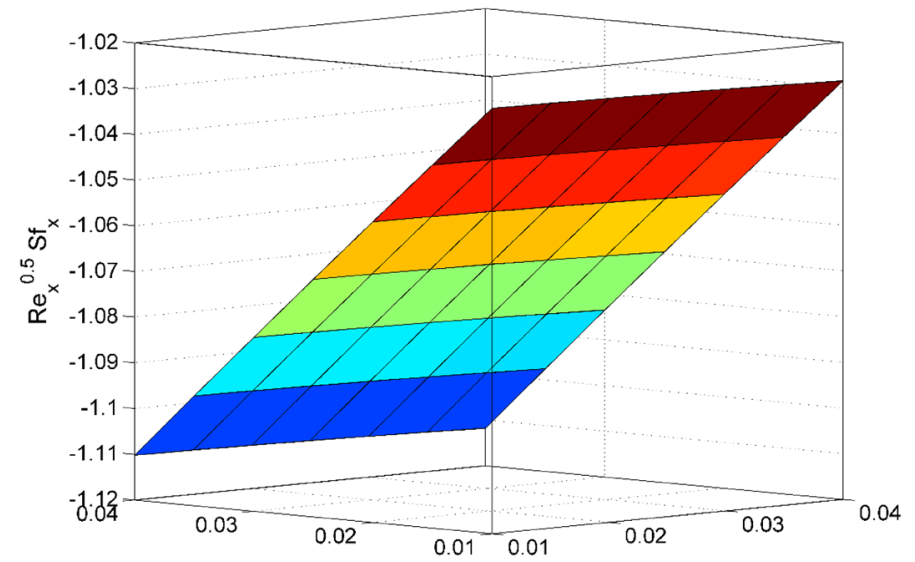

Ro

$\phi$

Figure 16. Effect of $\phi$ and $R o$ on $\operatorname{Re}_{\mathrm{x}}^{0.5} S f_{x}$.

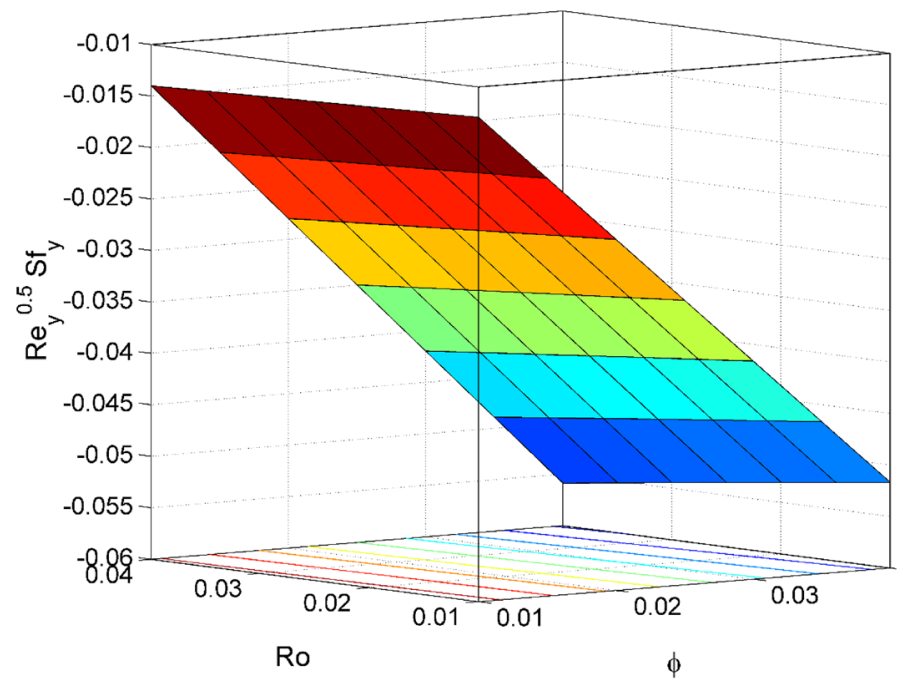

Figure 17. Effect of $\phi$ and $R o$ on $\operatorname{Re}_{\mathrm{y}}^{0.5} S f_{y}$. 


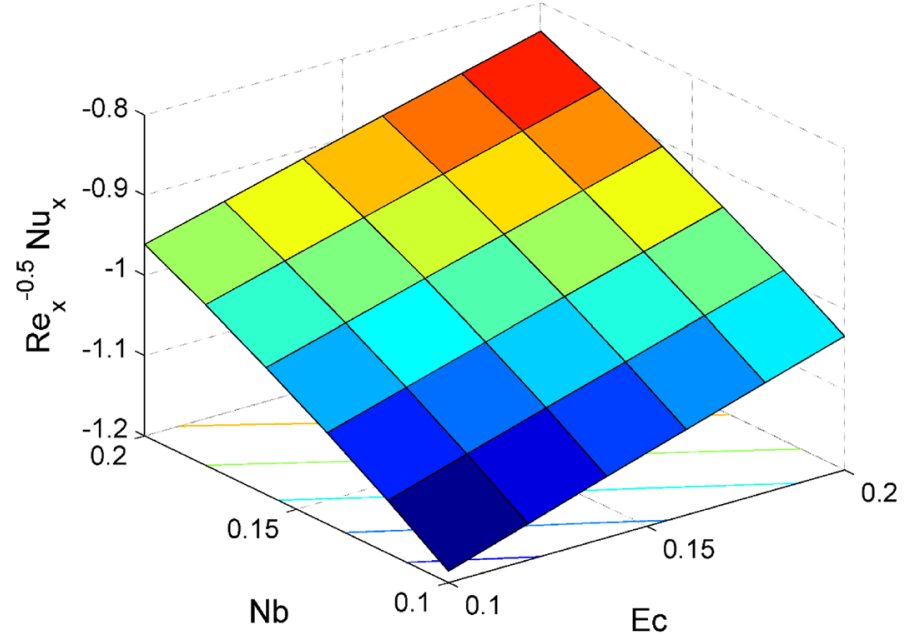

Figure 18. Effect of $N b$ and $E c$ on $\operatorname{Re}_{\mathrm{x}}^{-0.5} N u_{x}$.

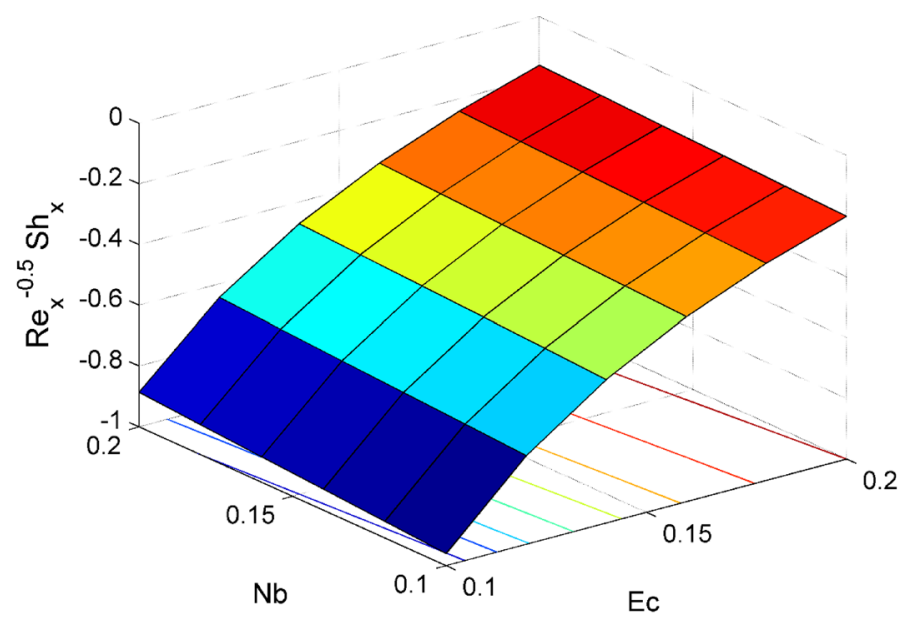

Figure 19. Effect of $N b$ and $E c$ on $\operatorname{Re}_{\mathrm{x}}^{-0.5} S h_{x}$.

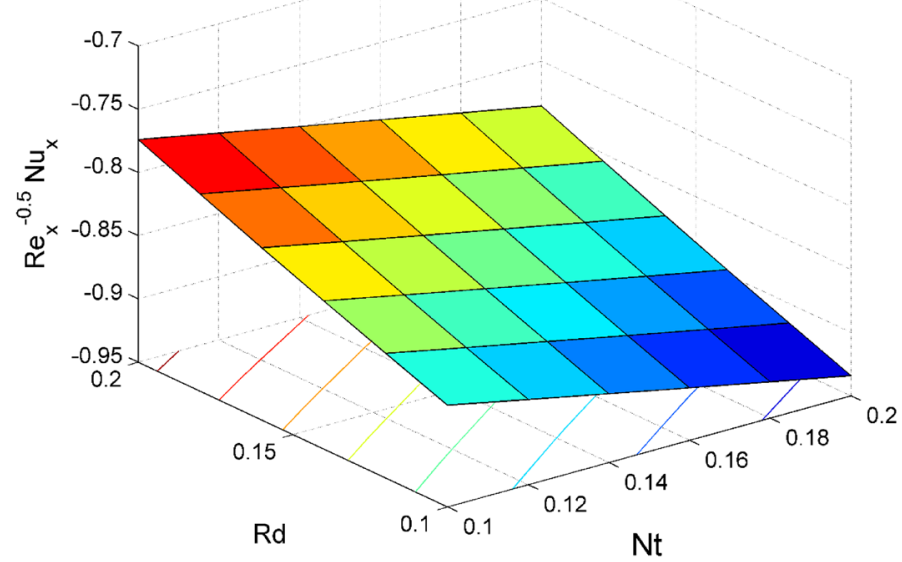

Figure 20. Effect of $R d$ and $N t$ on $\mathrm{Re}_{\mathrm{x}}^{-0.5} N u_{x}$. 


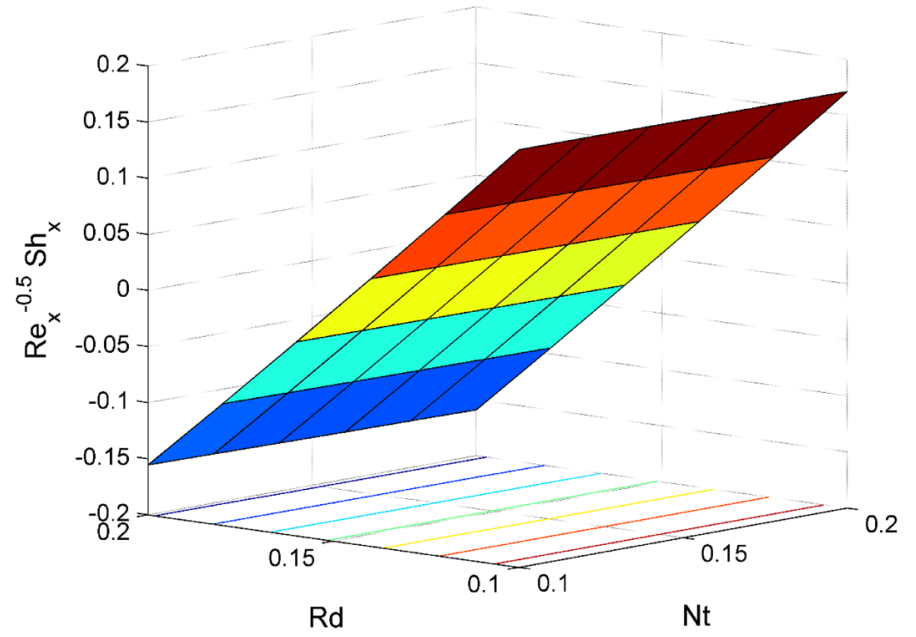

Figure 21. Effect of $R d$ and $N t$ on $\mathrm{Re}_{\mathrm{y}}^{-0.5} S h_{x}$.

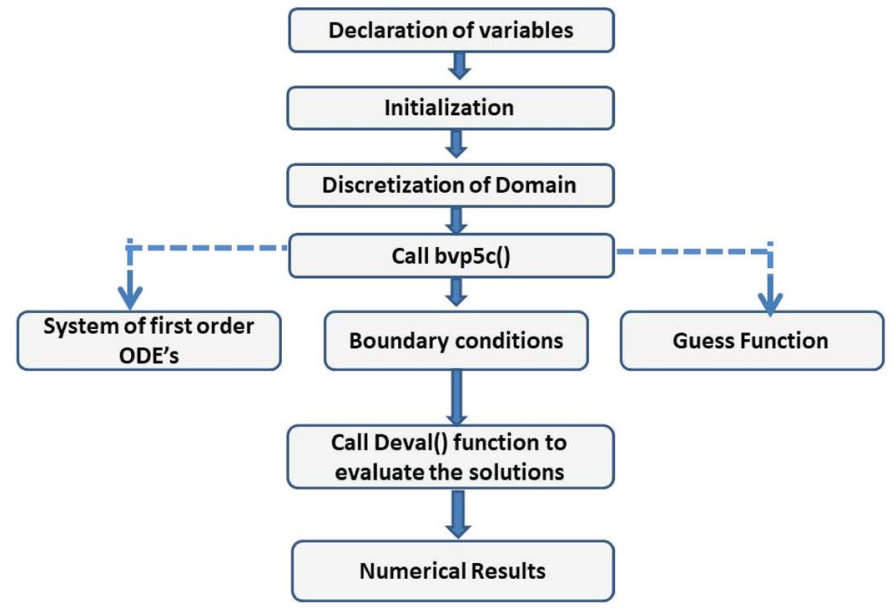

Chart 1. Algorithm of bvp5c method to solve boundary value problem.

\section{Appendix}

The system of linear ordinary differential equations is solved using bvp5c function using MATLAB software. It is essential to convert the nonlinear differential equations into the first-order system of equation. Then, the resultant first-order differential equations are treated using bvp $5 \mathrm{c}($ ) function. The basic syntax of bvp $5 \mathrm{c}$ function is sol=bvp4c(@OdeBVP,@OdeBC, solinit,options) where the four important arguments are defined as:

- @OdeBVP function that evaluates the differential equations $f(x, y)$ and can be written in the form of $d y d x=\operatorname{OdeBVP}(x, y$, parameters $)$.

- @OdeBC A function that computes the residual in the boundary conditions $b c(y(a), y(b))$. It can be written as res $=\operatorname{OdeBC}(y a, y b$, parameters $)$.

- solinit The guess structure formed with the helper function bvpinit and can be written in the form of solinit = bvpinit(linspace(etaMin,etaMax, stepsize),@OdeInit 1$)$.

- options Optional integration argument. A structure which create using the bvpset function. It can have the form options $=$ bvpset $\left(\right.$ 'name $1^{\prime}$, value $1,{ }^{\prime}$ name2', value $\left.1, \ldots\right)$.

The algorithm of the bvp $5 \mathrm{c}$ method is described in the Chart 1.

Received: 3 July 2021; Accepted: 1 October 2021

Published online: 19 October 2021

\section{References}

1. Choi, S. U. S. \& Eastman, J. A. Enhancing thermal conductivity of fluids with nanoparticles. In Proc. ASME Int. Mech. Eng. Congress and Exposition, Vol. 66 (1995). 
2. Khanafer, K., Vafai, K. \& Lightstone, M. Buoyancy-driven heat transfer enhancement in a two-dimensional enclosure utilizing nanofluids. Int. J. Heat Mass Transf. 46(19), 3639-3653 (2003).

3. Buongiorno, J. Convective transport in nanofluids. ASME J. Heat Transf. 128(3), 240-250 (2006).

4. Kuznetsov, A. V. \& Nield, D. A. Natural convective boundary-layer flow of a nanofluid past a vertical plate. Int. J. Therm. Sci. 49(2), 243-247 (2010).

5. Nield, D. A. \& Kuznetsov, A. V. The Cheng-Minkowycz problem for natural convective boundary-layer flow in a porous medium saturated by a nanofluid. Int. J. Heat Mass Transf. 52(25-26), 5792-5795 (2009).

6. Khan, W. A. \& Pop, I. Boundary-layer flow of a nanofluid past a stretching sheet. Int. J. Heat Mass Transf. 53(11-12), 2477-2483 (2010).

7. Makinde, O. D. \& Aziz, A. Boundary layer flow of a nanofluid past a stretching sheet with a convective boundary condition. Int. J. Ther. Sci. 50(7), 1326-1332 (2011).

8. Hayat, T. A. \& Muhammad, A. T. Influence of magnetic field in 3D flow of couple stress nanofluid over a nonlinearly stretching surface with convective condition. PLoS ONE 10, 0145332 (2015)

9. Hayat, T., Aziz, A., Muhammad, T. \& Alsaedi, A. On magnetohydrodynamic 3D flow of nanofluid over a convectively heated nonlinear stretching surface. Int. J. Heat Mass Transf. 100, 566-572 (2016).

10. Hayat, T., Muhammad, T., Shehzad, S. A., Alhuthali, M. S. \& Lu, J. Impact of magnetic field in three-dimensional flow of an Oldroyd-B nanofluid. J. Mol. Liq. 212, 272-282 (2015).

11. Khan, J. A. et al. On model for three-dimensional flow of nanofluid: An application to solar energy. J. Mol. Liq. 194, 41-47 (2014).

12. Gireesha, B. J., Gorla, R. S. R. \& Mahanthesh, B. Effect of suspended nanoparticles on three-dimensional MHD flow, heat and mass transfer of radiating Eyring-Powell fluid over a stretching sheet. J. Nanofluids 4(4), 474-484 (2015).

13. Mahanthesh, B., Mabood, F., Gireesha, B. J. \& Gorla, R. S. R. Effects of chemical reaction and partial slip on the three-dimensional flow of a nanofluid impinging on an exponentially stretching surface. Euro. Phys. J. Plus 132(3), 1-18 (2017).

14. Hayat, T., Muhammad, T., Alsaedi, A. \& Ahmad, B. Three-dimensional flow of nanofluid with Cattaneo-Christov double diffusion. Results Phys. 6, 897-903 (2016).

15. Oyelakin, I. S., Lalramneihmawii, P. C., Mondal, S., Nandy, S. K. \& Sibanda, P. Thermophysical analysis of three-dimensional magnetohydrodynamic flow of a tangent hyperbolic nanofluid. Eng. Rep. 2(4), 12144 (2020).

16. Yang, C., Li, W., Sano, Y., Mochizuki, M. \& Nakayama, A. On the anomalous convective heat transfer enhancement in nanofluids: Theoretical answer to the nanofluids controversy. J. Heat Transf. 135(5), 054504 (2013).

17. Malvandi, A., Moshizi, S. A., Soltani, E. G. \& Ganji, D. D. Modified Buongiorno's model for fully developed mixed convection flow of nanofluids in a vertical annular pipe. Comp. Fluids 89, 124-132 (2014).

18. Malvandi, A. \& Ganji, D. D. Mixed convection of alumina/water nanofluid in microchannels using modified Buongiorno's model in presence of heat source/sink. J. Appl. Fluid Mech. 9(5), 2277 (2016).

19. Sheikholeslami, M. \& Rokni, H. B. Numerical simulation for impact of on nanofluid heat transfer in a porous in presence of thermal radiation. Int. J. Heat Mass Transf. 118, 823-831 (2018).

20. Mahmoud, M. A. A. \& Megahed, A. M. Thermal radiation effect on mixed convection heat and mass transfer of a non-Newtonian fluid over a vertical surface embedded in a porous medium in the presence of thermal diffusion and diffusion-thermo effects. J. Appl. Mech. Tech. Phys. 54, 90-99 (2013).

21. Das, S., Jana, R. N. \& Makinde, O. D. Transient natural convection in a vertical channel filled with nanofluids in the presence of thermal radiation. Alex. Eng. J. 55, 253-262 (2016).

22. Shehzad, S. A., Abdullah, Z., Alsaedi, A., Abbasi, F. M. \& Hayat, T. Thermally radiative three-dimensional flow of Jeffrey nanofluid with internal heat generation and magnetic field. J. Mag. Mag. Mater. 397, 108-114 (2016).

23. Raza, J., Mebarek-Oudina, F., Ram, P. \& Sharma, S. MHD flow of non-Newtonian molybdenum disulfide nanofluid in a converging/diverging channel with Rosseland radiation. Defect Diffus. Forum 401, 92-106 (2020).

24. Wakif, A., Chamkha, A., Thumma, T., Animasaun, I. L. \& Sehaqui, R. Thermal radiation and surface roughness effects on the thermo-magneto-hydrodynamic stability of alumina-copper oxide hybrid nanofluids utilizing the generalized Buongiorno's nanofluid model. J. Ther. Anal. Calor. 143, 1201-1220 (2020).

25. Alam, M. W. et al. CPU heat sink cooling by triangular shape micro-pin-fin: Numerical study. Int. Commun. Heat Mass Transf. 112, 104455 (2020).

26. Baslem, A. et al. Analysis of thermal behavior of a porous fin fully wetted with nanofluids: Convection and radiation. J. Mole. Liq. 307, 112920 (2020).

27. Ganesh Kumar, K. et al. Significance of Arrhenius activation energy in flow and heat transfer of tangent hyperbolic fluid with zero mass flux condition. Microsyst. Technol. 26, 2517-2526 (2020).

28. Punith Gowda, R. J. et al. Thermophoretic particle deposition in time-dependent flow of hybrid nanofluid over rotating and vertically upward/downward moving disk. Surf. Interface 22, 100864 (2021).

29. Ahmadian, A., Bilal, M., Khan, M. A. \& Asjad, M. I. Numerical analysis of thermal conductive hybrid nanofluid flow over the surface of a wavy spinning disk. Sci. Rep. 10, 18776 (2020).

30. Ahmadian, A., Bilal, M., Khan, M. A. \& Asjad, M. I. The non-Newtonian maxwell nanofluid flow between two parallel rotating disks under the effects of magnetic field. Sci. Rep. 10, 17088 (2020).

31. Lv, Y. P. et al. Numerical approach towards gyrotactic microorganisms hybrid nanoliquid flow with the hall current and magnetic field over a spinning disk. Sci. Rep. 11, 8948 (2021).

32. Lund, L. A., Omar, Z., Dero, S., Baleanu, D. \& Khan, I. Rotating 3D flow of hybrid nanofluid on exponentially shrinking sheet: Symmetrical solution and duality. Symmetry 12(10), 1637 (2020).

33. Shampine, L. F. \& Kierzenka, J. A BVP solver that controls residual and error. J. Numer. Anal. Ind. Appl. Math. 3(1-2), 27-41 (2008).

\section{Author contributions}

This is to confirm that the three authors had worked equally on the final article. This includes the formulation, analysis, producing figures, and discussing all the results. Moreover, the three authors had contributed equally in writing the final manuscript as well.

\section{Competing interests}

The authors declare no competing interests.

\section{Additional information}

Correspondence and requests for materials should be addressed to W.A.-K.

Reprints and permissions information is available at www.nature.com/reprints.

Publisher's note Springer Nature remains neutral with regard to jurisdictional claims in published maps and institutional affiliations. 
(c) (i) Open Access This article is licensed under a Creative Commons Attribution 4.0 International cc) License, which permits use, sharing, adaptation, distribution and reproduction in any medium or format, as long as you give appropriate credit to the original author(s) and the source, provide a link to the Creative Commons licence, and indicate if changes were made. The images or other third party material in this article are included in the article's Creative Commons licence, unless indicated otherwise in a credit line to the material. If material is not included in the article's Creative Commons licence and your intended use is not permitted by statutory regulation or exceeds the permitted use, you will need to obtain permission directly from the copyright holder. To view a copy of this licence, visit http://creativecommons.org/licenses/by/4.0/.

(C) The Author(s) 2021, corrected publication 2021 